\title{
Maternal and fetal out come in meconium stained amniotic fluid in a tertiary centre
}

\author{
Sadiq Unnisa*, Sowmya B.S., Smitha B. Rao, Rajagopal K.
}

Department of Obstetrics \& Gynaecology, Yenepoya Medical College, Mangalore, India

Received: 18 January 2016

Accepted: 15 February 2016

\section{*Correspondence:}

Dr. Sadiq Unnisa,

E-mail: drsadiqa12@gmail.com

Copyright: ( ) the author(s), publisher and licensee Medip Academy. This is an open-access article distributed under the terms of the Creative Commons Attribution Non-Commercial License, which permits unrestricted non-commercial use, distribution, and reproduction in any medium, provided the original work is properly cited.

\section{ABSTRACT}

Background: This study was undertaken to determine the correlation of amniotic fluid stained with meconium (MSAF) with maternal and fetal outcome.

Methods: This prospective observational study was carried out in the Department of obstetrics and gynecology, Yenepoya medical college, Mangalore over a period of 14 months between January 2013 to march 2014. A total of 1000 pregnant women who had completed more than 37 weeks of gestation with singleton pregnancies \& cephalic presentation were included in this study. MSAF on spontaneous or artificial rupture of membranes were monitored during labour with fetal heart rate abnormality, consistency of liquor, 1 minute and 5 minute Apgar score, LSCS, instrumental delivery, NICU admissions and neonatal complications as outcome variables.

Results: Women were divided into two groups: 350 women with MSAF as cases, while 650 women with clear liquor were taken as controls. Among 350 cases with MSAF, $70 \%$ were unbooked and $30 \%$ were booked pts. About $75.7 \%$ of women were between 20-30 years of age-group. Primi gravidas constituted $51.4 \%$ in study group. Approximately $41.4 \%$ cases had gestational ages of $39-39+6$. Among MSAF $55.4 \%$ were thin stained \& $44.5 \%$ were thickly stained. $45.7 \%$ showed fetal heart abnormalities on electronic monitoring \& presence of fetal bradycardia was higher. Caesarean section rates were nearly triple in cases $(45.7 \%$ vs $15.7 \%)$. Fetal out come in regard to Apgar score at birth, birth asphyxia, MAS, increased NICU admissions were more in cases. Incidence of Male to female was high $(52.6 \%$ vs $47.3 \%)$.

Conclusions: Presence of MSAF is worrisome for both the obstetrician and pediatricians view as it increases surgical intervention, birth asphyxia, MAS \& NICU admissions.

Keywords: Meconium stained liquor, Term gestation, Apgar score birth asphyxia, MAS

\section{INTRODUCTION}

A substance which accumulates in the fetal bowel during the intra uterine life is called meconium. About $69 \%$ of new-borns pass meconium by 12 hours of age, but some fetuses pass meconium prior to birth as well. ${ }^{1}$ Incidence of meconium stained amniotic fluid ranges from 1.5$18 \% .^{2}$ The fetuses pass meconium in response to hypoxia therefore signals fetal compromise, alternatively in utero passage may represent normal gastrointestinal tract maturation under neuronal control. ${ }^{3}$ Passage of meconium is rare before 34 weeks of gestation and incidence steadily increases beyond 37 weeks of gestation. ${ }^{4}$ Factors like placental insufficiency, maternal hypertension, preeclampsia, oligohydramnios and maternal drug abuse may result in passage of meconium in in-utero. ${ }^{5}$

The presence of amniotic fluid stained with meconium is subject of importance when considering Intrapartum management. Usually meconium has been viewed as a harbinger of impending or on-going compromise in the fetus. Foetuses born with MSAF are more likely to 
develop respiratory distress than born with clear liquor. ${ }^{6}$ Few investigators observed that it is not associated with fetal hypoxia, acidosis, and fetal distress, others found low apgar scores in meconium stained newborns. ${ }^{7}$ The predictive value of MSAF was better when it is occurs in high risk patients and is thick. Lightly stained meconium had poor correlation with fetal hypoxia. ${ }^{8}$ The thick meconium group has a significantly greater risk of an abnormal FHR tracing, a 1 and 5 minute Apgar score less than 7, a cord blood $\mathrm{pH}$ of less than 7.2, sepsis, need for Oxygen support and NICU admission of babies. ${ }^{7}$ Presence of thick meconium in amniotic fluid is a predisposing factor towards adverse perinatal outcome in the form of aspiration and its sequelae.

Meconium present below the vocal cords is known as meconium aspiration, the incidence is around $20-30 \%$ of all infants with MSAF. ${ }^{9}$ Aspiration can occur in utero with fetal gasping, or after birth, with the first breaths of life. Aspiration of the meconium into fetal or neonatal lungs is associated with clinical disease ranging from mild respiratory distress to severe respiratory compromise and causes significant increase in perinatal morbidity and mortality. ${ }^{10}$ Meconium aspiration syndrome (MAS) is defined as a respiratory distress that develops shortly after birth, with radiographic evidence of aspiration pneumonitis and presence of meconium stained amniotic fluid. ${ }^{11}$ MAS can occur in about $5 \%$ of deliveries with meconium-stained amniotic fluid and death occurs in about $12 \%$ of infants with MAS. ${ }^{9,12}$ Considering the risk of MASF, this study was under taken with an objective to correlate the maternal and fetal out come in those deliveries where there was meconium stained liquor \& to determine the of adverse fetal outcome associated with MSAF.

\section{METHODS}

The present prospective observational study was carried out in the department of Obstetrics and Gynaecology, Yenepoya medical college, Mangalore, over a period of 14 months from January 2013 to march 2014.

All pregnant women who were more than 37 weeks of gestation to $40^{6}$ weeks with singleton pregnancies, and cephalic presentation, with no known fetal anomalies, spontaneous onset of labour, in whom presence of meconium in amniotic fluid on spontaneous rupture of membranes (SRM) or artificial rupture of membranes (ARM) were included in the study after proper consent.

Exclusion criteria- included pregnancies < 37wks, pregnancies $>41 \mathrm{wks}$, high risk pregnancies or pregnancies with severe maternal diseases, any fetal anomalies, maternal age more than 35yrs, antepartum fetal death, intra uterine growth retardation, non-cephalic presentations, placenta Previa, induction of labour, and maternal systemic diseases.
Ethical clearance was obtained from institutional ethical committee.

One thousand pregnant women were included in the study, 350 were cases with meconium stained amniotic fluid (MSAF) and 650 were controls with clear amniotic fluid. Meconium was graded thick when amniotic fluid was viscous tenacious \& contained large particulate material, thin if fluid was normal with greenish colouring. All the information regarding cases and controls were noted in a predesigned proforma. The labour was monitored electronically, the mode of delivery, Apgar scores at one and five minutes, birth weight, neonatal intensive care (NICU) admissions, birth asphyxia, meconium aspiration syndrome (MAS), early neonatal deaths were recorded. The data was analysed using chi square test.

\section{RESULTS}

Table 1: Prevalence of MSAF in relation to booking states maternal age, parity, gestational age.

\begin{tabular}{|llll|}
\hline Parameters & & Case (\%) & Control (\%) \\
\hline Booked & & $105(30 \%)$ & 380 \\
\hline Unbooked & & $245(70 \%)$ & 270 \\
\hline $\begin{array}{l}\text { Maternal } \\
\text { age }\end{array}$ & $<20 y r s$ & $50(14.3 \%)$ & $70(10.7 \%)$ \\
\cline { 2 - 4 } & $21-30$ & $265(75.7 \%)$ & $405(62.3 \%)$ \\
\hline \multirow{3}{*}{ Parity } & Primi & $180(51.4 \%)$ & $406(62.4 \%)$ \\
\hline \multirow{3}{*}{$\begin{array}{l}\text { Gestational } \\
\text { age }\end{array}$} & $\begin{array}{l}37-37 \\
+6\end{array}$ & $48(13.7 \%)$ & $125(19.2 \%)$ \\
\cline { 2 - 4 } & $38-38^{+6}$ & $68(19.6 \%)$ & $175(26 \%)$ \\
\hline & $39-39^{+6}$ & $145(41.4 \%)$ & $226(34.7 \%)$ \\
\hline
\end{tabular}

Table 2: Intrapartum meconium staining.

\begin{tabular}{|lllll|}
\hline \multirow{2}{*}{ Meconium } & & Number & Percentage & P value \\
\cline { 2 - 5 } & Thick & 156 & $44.5 \%$ & $<.001$ \\
\cline { 2 - 5 } & Thin & 194 & $55.4 \%$ & $<0.001$ \\
\hline
\end{tabular}

Table 3: Indications of LSCS in MSAF.

\begin{tabular}{|c|c|c|c|c|c|}
\hline \multirow{2}{*}{ Parameter } & \multirow{2}{*}{$\begin{array}{l}\text { No. } \\
\text { of } \\
\text { cases }\end{array}$} & \multicolumn{2}{|c|}{ Meconium } & \multirow{2}{*}{ Control } & \multirow{2}{*}{$\begin{array}{l}P \\
\text { value }\end{array}$} \\
\hline & & Thick & Thin & & \\
\hline $\begin{array}{l}\text { Fetal } \\
\text { bradycardia }\end{array}$ & 94 & $\begin{array}{l}58 \\
(61.7)\end{array}$ & $\begin{array}{l}36 \\
(38.2)\end{array}$ & 10 & $<0.001$ \\
\hline $\begin{array}{l}\text { Fetal } \\
\text { tachycardia }\end{array}$ & 66 & $\begin{array}{l}43 \\
(65.2)\end{array}$ & $\begin{array}{l}23 \\
(34.8)\end{array}$ & 7 & $<0.001$ \\
\hline
\end{tabular}

During the study period there were 1678 deliveries in our institute, 1000 consecutive deliveries met the inclusion criteria. Women were divided into two groups 350 served as cases with MSAF, while 650 women clear amniotic fluid were taken as controls. 
Table 4: Mode of delivery.

\begin{tabular}{|llll|}
\hline Parameter & No. of cases & Control & P value \\
\hline $\begin{array}{l}\text { Normal } \\
\text { delivery }\end{array}$ & $173(49.5 \%)$ & $536(82.5 \%)$ & 0.161 \\
\hline $\begin{array}{l}\text { Vacuum } \\
\text { delivery }\end{array}$ & $17(4.8 \%)$ & $15(2.5 \%)$ & 0.310 \\
\hline LSCS & $160(45.7 \%)$ & $99(15.2 \%)$ & $<0.001$ \\
\hline $\begin{array}{l}\text { Puerperal } \\
\text { fever }\end{array}$ & $20(5.6 \%)$ & $20(3 \%)$ & 0.012 \\
\hline
\end{tabular}

Among 350 cases with MSAF 70\% were unbooked \& $30 \%$ were booked (at least 3 visits, with first visit in first trimester), $75.7 \%$ were between $20-30$ years of age group. Primigravida's constituted $51.4 \%$ in the study group. Approximately $41.4 \%$ had gestational ages of 39 $39^{6}$ weeks as compared to controls $(34.7 \%)$ suggesting that advancing gestational age increased meconium staining of amniotic fluid (Table 1). Among MSAF $55.4 \%$ were thin stained and $44.5 \%$ were thickly stained (Table 2). Fetal heart rate abnormalities were detected by continuous electronic monitoring \& presence of fetal bradycardia was higher in cases as compared to controls (Table 3).

Caesarean section done commonly in cases of MSAF accounted for $45.7 \%$ as compared to $15.2 \%$ in controls. Normal deliveries were $49.5 \%$ in cases and $82.5 \%$ in controls. Approximately $4.8 \%$ cases had instrumental delivery while in control group was $2 \%$ (Table 4 ).

Table 5: Perinatal outcome.

\begin{tabular}{|llll|}
\hline Parameter & No. of cases & Control & P value \\
\hline $\begin{array}{l}\text { Asymptomatic } \\
\text { at birth }\end{array}$ & $\begin{array}{l}211 \\
(60.2 \%)\end{array}$ & $\begin{array}{l}480 \\
(73.8 \%)\end{array}$ & $<0.001$ \\
\hline $\begin{array}{l}\text { Apgar score } \\
1^{\prime}<7\end{array}$ & $\begin{array}{l}100 \\
(28.5 \%)\end{array}$ & $\begin{array}{l}92 \\
(14.15 \%)\end{array}$ & $<0.001$ \\
\hline $\begin{array}{l}\text { Apgar score at } \\
5 \text { ' }<7\end{array}$ & $39(11.2 \%)$ & $78.12 \%$ & $<0.001$ \\
\hline Birth asphyxia & $45(12.8 \%)$ & $20(3 \%)$ & $<0.001$ \\
\hline MAS & $125(35 \%)$ & - & $<0.001$ \\
\hline $\begin{array}{l}\text { NICU } \\
\text { admission }\end{array}$ & $\begin{array}{l}290 \\
(82.8 \%)\end{array}$ & $137(21 \%)$ & $<0.001$ \\
\hline $\begin{array}{l}\text { Intrapartum } \\
\text { death }\end{array}$ & 3 & - & 0.034 \\
\hline $\begin{array}{l}\text { Early neonatal } \\
\text { deaths }\end{array}$ & $7(2 \%)$ & $2(0.3 \%)$ & 0.086 \\
\hline
\end{tabular}

In $60.2 \%$ cases babies were asymptomatic at birth as compared to $73.8 \%$ in controls. Babies with MSAF had low Apgar score at 1 minute $(28.5 \%)$ cases required NICU admissions. MAS were seen in $35 \%$ of cases. Incidence of birth asphyxia was higher among the babies born to cases than the babies in controls. Early neonatal deaths were seen in 7 babies born among cases (Table 5). Table 6 shows that no much difference was observed in terms of birth weight between cases and controls.
Table 6: Birth weights.

\begin{tabular}{|lll|}
\hline Birth weights & Cases & Control \\
\hline$<2.5 \mathrm{~kg}$ & 35 & 126 \\
\hline $2.6-3 \mathrm{~kg}$ & 202 & 394 \\
\hline$>3 \mathrm{~kg}$ & 113 & 130 \\
\hline
\end{tabular}

\section{DISCUSSION}

Detection of MSAF during labour causes apprehension \& anxiety to the health provider, as it is often considered as an indicator of fetal distress. ${ }^{13}$ It is a frequent cause for poor fetal outcome, as it increases the number of neonatal intensive care unit admissions. However the literature in obstetrics still has many unanswered questions regarding the significance of MSAF \& the appropriate protocols for the management.

This study, in accordance with the study done by Bhide et al showed that majority of the cases were unbooked. ${ }^{14}$ We found that the incidence of MSAF was higher in the age group of 21-30 years which was similar to that as seen in Sanduss et al study, this seemed to be an incidental finding. ${ }^{15}$ Sunoo et al found significant increase rate of MSAF at 39weeks of gestation, similarly in our study we found that the rate of meconium staining increased with gestational age. ${ }^{16}$ Sedaghatian et al \& Sandu SS have observed similar results. ${ }^{15,17}$ In present study showed MSAF were common in primigravidas $51.4 \%$ which was consistent with Becker et al. ${ }^{18}$

Saunder's et al reported that caesarean sections were performed twice as frequently in subjects with MSAF. ${ }^{19}$ In comparison with their study, caesarean section rates were triple as compared to controls. Our study had caesarean section rate of $45 \%$ which were due to abnormal fetal heart rate patterns associated with MSAF and reflects partly the care provider's dilemma in managing such labours as they become more concerned about the fetuses. In contrast to our study, Wong SF found that $13.2 \%$ of MSAF had caesarean section as compared to $8.8 \%$ in controls. Abnormal FHR were also found significantly high in cases which were similar to Berkus et al study. ${ }^{7}$ Incidences of fetal heart rate abnormalities were higher in thick meconium than thin. Meconium consistency is directly correlated to the fetal outcome. The risk of perinatal mortality increases when meconium is present at the onset of labour and is thick. ${ }^{21}$

In our study $60 \%$ of infants were asymptomatic at birth, $28.5 \%$ of babies had low Apgar score at 1 minute, $10 \%$ at 5 mins. Sedaghatian ${ }^{17}$ study found similar results, Wiswell et al found significantly lower 1 minute apgar score in MSAF neonate but not at 5 minutes. ${ }^{9}$

Incidence of birth asphyxia was more in cases than in controls. Khatun et al found similar results in her study. Requirement of oropharyngeal suction was more in MSAF. ${ }^{22}$ Meconium aspiration syndrome developed in $34.7 \%$ among them it was higher in thick meconium. 
Admission to NICU was more in cases \& neonatal mortality was also higher in cases than controls. In the present study NICU admission was $54.7 \%$ and neonatal mortality was $2 \%$. Khatun et al study showed $2.9 \%$ mortality in cases $\& 1.4 \%$ in controls. ${ }^{22}$

\section{CONCLUSIONS}

Passage of meconium still remains as an enigma to the obstetrician and equally worries the paediatrician. However as shown in the study thick meconium are associated with increased operative interventions, low apgar scores, increased risk of birth asphyxia, meconium aspiration syndrome, and NICU admissions. However thin meconium is shown to have lesser perinatal complication thus identifying women at risk for the passage of mecinium in utero, intra partum monitoring so as to reduce the perinatal morbidity and mortality. Presence of MSAF needs close monitoring of fetus with CTG, mindful intervention, and presence of skilled paediatrician at the time of birth.

\section{ACKNOWLEDGEMENTS}

We acknowledge the help provided by our institute's statistician and Ms. Geetha who helped with typing.

\section{Funding: No funding sources}

Conflict of interest: None declared

Ethical approval: The study was approved by the Institutional Ethics Committee

\section{REFERENCES}

1 Wood CL. Meconium stained amniotic fluid J Nurse Midwifery. 1994;39(2 Suppl):106S-9S.

2 Katz VL, Bowes WA Jr. Meconium aspiration syndrome: reflections on a murky subject. Am J Obstet Gynecol. 1992;166:171-83.

3 Mitchell J, Schulman H, Fleischer A. Meconium aspiration fetal acidosis. Obstet Gynecol. 1985;65:352-5.

4 Steer PJ, Eigbe F, Lissauer TJ, Beard RW. Interrelationships among abnormal cardiotocograms in labor, meconium staining of the amniotic fluid, arterial cord blood $\mathrm{pH}$, and Apgar scores. Obstet Gynecol. 1989;74(5):715-21.

5 Shaik EM, Mehmood S, Shaik MJ. Neonatal outcome in meconium stained amniotic fluid-one year experience. J PakMed Assoc. 2010;60(9):711-4.

6 Fleisher A, Anyaeghunam A, Guidetti D, Randolph G, Merkartz IR. Persistant clinical problem:profile of the term infant with significant respiratory complications. obstet Gynecol. 1992;79:185-90.

7 Berkus MD, Langer O, Samueloff A, Xenakis EM, Field NT, Ridgway LE. Meconium-stained amniotic fluid: increased risk for adverse neonatal outcome. Obstet Gynecol. 1994;84(1):115-20.

8 Ratnam SS, Bhaskar Rao K, Arulkumaran S. Practical approach to Intrapartum fetal monitoring in labour. Chapter 12. Obstetrics and Gynecology for Postgraduates. 1992;1:115-25.

9 Wiswell TE, Bent RC. Meconium staining and the meconium aspiration syndrome. Unresolved issues. Pediatr Clin North Am. 1993;40:955-81.

10 Mukhopadhyay PN, Dalui R, Hazra S. Role of Intrapartum amnioinfusion in meconium stained amniotic fluid. The Journal of Obstetrics and Gynaecology of India. 2006;563:230-2.

11 Klinger M C, Kruse J. Meconium aspiration syndrome: pathophysiology and prevention. J Am Board Fam Med.1999;12(6).

12 Cleary GM, Wiswell TE. Meconium-stained amniotic fluid and the meconium aspiration syndrome. An update. Pediatr Clin North Am. 1998;45:511-29.

13 Naqvi SB, Manzoor S. Association of meconium stained amniotic fluid with perinatal outcome in pregnant women of 37- 42 weeks gestation. Pak J Surg. 2011;27(4):292-8.

14 Bhide SS, Shedurnikar N, Aiyer S, Baxi SR. Neonatal outcome after meconium stained amniotic fluid. J Obstet Gynecol India. 1993;44:933-5.

15 Sandhu SK, Singh J. Critical evaluation of meconium staining of amniotic fluid and fetal outcome. . J Obstet Gynecol India. 1993;43:528-53.

16 Sunoo CS, Kosasa TB, Nakayama RT, Hale RW. The incidence of meconium aspiration in Hawaii.Hawaii Med J. 1993;52:290-3.

17 Sedaghatian MR, Otheman L, Rashid N, Ramachandran P, Bener BA. An 8 year study of meconium stained amniotic fluid in different ethnic groups. Kuwait Medical Journal. 2004;36:266-9.

18 Becker S, Solomayer E, Dogan C, Wallwiener D, Fehm T. Meconiun stained amniotic fluid perinatal outcome and obstetrical management in low -risk sub urban population. Eur J Obstet Gynecol Reprod Biol. 2007;132(1):46-50. .

19 Saunders K. Should we worry about meconium? A controlled study of neonatal outcome. Trop Doct. 2002;32(1):7-10.

20 Wong WS, Wong KS, Chang A. Epidemiology of meconium staining of amniotic fluid in Hong Kong. Aust NZJ Obstet Gynaecol. 1985;25(2):90-3.

21 Rossi EM, Philipson EH, Williams TG, Kalhan SC. Meconium aspiration syndrome: Intrapartum and neonatal attributes. Am J Obstet Gynecol. 1998;10:107-27.

22 Khatun M, Arzu J, Haque E, Kamal M, Manum M, Khan M. Fetal out come in deliveries with meconium stained liquor, Bangladesh $\mathrm{J}$ child health. 2009;33:41-5.

Cite this article as: Unnisa S, Sowmya BS, Rao SB, Rajagopal K. Maternal and fetal out come in meconium stained amniotic fluid in a tertiary centre. Int J Reprod Contracept Obstet Gynecol 2016;5:8137. 